\title{
ARTICLE OPEN \\ Relationship between somatostatin and death receptor expression in the orbital frontal cortex in schizophrenia: a postmortem brain mRNA study
}

\author{
Dipesh Joshi ${ }^{1,2,3}$, Vibeke S Catts ${ }^{1,2,3}$, Juan C Olaya ${ }^{1,2,3}$ and Cynthia Shannon Weickert ${ }^{1,2,3}$
}

BACKGROUND: Recently, we provided evidence showing reductions in GAD67 and Dlx mRNAs in the orbital frontal cortex (OFC) in schizophrenia. It is unknown whether these reductions relate mainly to somatostatin (SST) or parvalbumin (PV) mRNA expression changes, and/or whether these reductions are related to decreased SST mRNA+ interneuron density.

AIMS: To determine whether inhibitory interneuron deficits in the OFC from people with schizophrenia are greatest for SST or PV mRNAs, and whether any such deficits relate to mRNAs encoding cell death signalling molecules.

METHODS: Inhibitory interneuron mRNAs (SST; PV: in situ hybridization, quantitative PCR (qPCR)) and death signaling mRNAs [FAS receptor (FASR); TNFSF13: qPCR] were measured in control and schizophrenia subjects (38/38). SST mRNA+ interneuron-like cells were quantified in layer II in the gyrus rectus. Gray matter SST and PV mRNAs were correlated with interstitial white matter neuron (IWMN) density (GAD65/67; NeuN) and death signaling mRNAs.

RESULTS: SST mRNA was reduced in OFC layers I-VI in schizophrenia (both in situ and qPCR), with greatest deficit in layer II (67\%). Layer II SST mRNA+ neuron density was reduced in schizophrenia ( 29\%). PV mRNA was reduced in layers III (18\%) and IV (31\%) with no significant diagnostic difference in PV mRNA measured by qPCR. FASR mRNA was increased in schizophrenia (34\%). SST, but not PV, expression correlated negatively with FASR and TNFSF13 expressions and with IWMN density.

CONCLUSIONS: Our study demonstrates that SST interneurons are predominantly linked to the inhibitory interneuron pathology in the OFC in schizophrenia and that increased death receptor signaling mRNAs relate to prominent laminar deficits in SST mRNA in the OFC in schizophrenia. We suggest that SST interneurons may be more vulnerable to increased death receptor signaling than PV interneurons.

npj Schizophrenia (2015) 1, Article number: 14004; doi:10.1038/npjschz.2014.4; published online 4 March 2015

\section{INTRODUCTION}

The orbital frontal cortex (OFC) is located on the ventral surface of the frontal lobe and is considered to be a major node of the social brain network. ${ }^{1}$ Abnormalities, including volume deficits, in the OFC in schizophrenia have been demonstrated in neuropsychological, ${ }^{2}$ functional, ${ }^{3}$ and structural ${ }^{4,5}$ magnetic resonance imaging studies. People with OFC lesions show abnormal behaviors, such as social-emotional deficits, which are also common to people with schizophrenia. ${ }^{6}$

Our recent work has demonstrated that the inhibitory interneuron deficits observed in the dorso-lateral prefrontal cortex $(\mathrm{DLPFC})^{7,8}$ extend to and are greater in magnitude in the OFC ${ }^{9,10}$ in schizophrenia. Among the interneuron mRNAs quantified in the prefrontal cortex, we found the greatest deficit in somatostatin (SST) mRNA, ${ }^{8,11}$ which is consistent with reports demonstrating SST mRNA deficits in schizophrenia, ${ }^{12-14}$ whereas others find parvalbumin (PV) expression to be predominantly reduced in schizophrenia. ${ }^{15-17}$ Despite evidence suggesting that SST interneurons are the most affected in schizophrenia, $8,11,14$ much of the research focus has been on developing animal models for schizophrenia that are consistent with deficits in predominantly PV interneurons. ${ }^{18,19}$ Further, the nature and magnitude of deficit for the two prominent inhibitory interneuron mRNAs (SST and PV) are still unclear in the OFC in schizophrenia.

It remains controversial whether reductions in inhibitory interneuron mRNAs (particularly SST and PV) represent reductions in interneuron numbers in people with schizophrenia. Although there are reports demonstrating a reduction in non-pyramidal/ interneuron-like cells, ${ }^{16,20-22}$ others report an increase or no change in interneuron density in schizophrenia. ${ }^{23-26}$ Although some ${ }^{16,20,22,27}$ propose that non-pyramidal/interneuron-like cell density is reduced in schizophrenia, others ${ }^{28}$ interpret decreased interneuron mRNA+ neurons as a reduction in mRNA per cell, with no change in cell density. ${ }^{13,28-30}$

One possible mechanism by which cortical neurons may decrease in number or density is through activation of apoptopic pathways. The possible role of apoptosis in the pathophysiology of schizophrenia remains a topic of interest for schizophrenia researchers, with neurodevelopmental insults and neuronal loss being linked to apoptosis. ${ }^{20,31-33}$ Cortical volume loss coupled with possible reduction in inhibitory interneurons in people with schizophrenia raises the question as to whether interneurons are undergoing cell death? A recent study by our group, for the first time, demonstrated elevated death receptor signaling mRNAs

${ }^{1}$ Schizophrenia Research Institute, Liverpool Street, Darlinghurst, NSW, Australia; ${ }^{2}$ Neuroscience Research Australia, Barker Street, Randwick, NSW, Australia and ${ }^{3}$ School of Psychiatry, Faculty of Medicine, University of New South Wales, Sydney, NSW, Australia.

Correspondence: C Shannon Weickert (c.weickert@neura.edu.au)

Received 22 August 2014; revised 20 October 2014; accepted 20 October 2014 
[FAS receptor (FASR); TNFSF13] in the DLPFC in schizophrenia and showed that this relates to reduced inhibitory interneuron mRNAs (SST; PV). ${ }^{34}$ TNFSF13 is a ligand for tumor necrosis factor receptor family members. ${ }^{34}$ Among the different receptor subtypes in this family (FAS, DR3, DR4, DR5), ${ }^{35,36}$ FASR $^{36,37}$ is widely expressed in the central nervous system, whereas the other three receptors have a limited expression. ${ }^{3}$ TNFSF13-FASR signaling leads to activation of caspases $(8,10,3,6$, and 9) resulting in cellular apoptosis by DNA degradation and membrane blebbing. ${ }^{34,39}$

In our present study, we test for layer-specific changes in SST and PV mRNAs in the OFC in people with schizophrenia compared with controls. We also determine the relative expression of death receptor signaling markers (FASR; TNFSF13) in schizophrenia and control subjects and explore how these relate to changes in SST and PV mRNAs in the OFC.

\section{MATERIALS AND METHODS}

Human postmortem brain tissue samples

OFC tissue from people with schizophrenia or schizoaffective disorder $(n=38)$ and control subjects $(n=38)$ was obtained from the New South Wales Tissue Resource Centre (Sydney, Australia; Human Research Ethics Committee 07261; see Table 1). ${ }^{40}$ Groups were matched for age, brain $\mathrm{pH}$ and postmortem interval. Tissue sections $(14 \mu \mathrm{m})$ were sliced from fresh frozen blocks (gyrus rectus, Brodmann area 11).

\section{In situ hybridization}

OFC tissue sections (two per case per probe) were thawed, fixed acetylated, delipidated, and dehydrated as described earlier. ${ }^{10}$ Hybridization buffer-containing ${ }^{35} \mathrm{~S}$-uracil triphosphate-labeled SST (specific activity $=1.81 \times 10^{9}$ c.p.m. $/ \mu \mathrm{g}$ ) or PV (specific activity $=2.12 \times 10^{9}$ c.p.m. $/$ $\mu \mathrm{g})$ riboprobe $(5 \mathrm{ng} / \mathrm{ml}$; see Supplementary Information for details) was incubated on each section overnight at $55^{\circ} \mathrm{C}$ in humidified chambers. As a control, $5 \mathrm{ng} / \mathrm{ml}$ of ${ }^{35} \mathrm{~S}$-UTP-labeled SST or PV sense riboprobe was applied to additional sections. Following post-hybridization RNase digestion, slides were washed and exposed to BioMax MR (Kodak, Rochester, NY, USA) autoradiographic film (SST-9 weeks; PV-5 weeks) with ${ }^{14} \mathrm{C}$ standards (American Radiolabeled Chemicals, St Louis, MO, USA). To determine SST mRNA localization at the cellular level, all slides were dipped in NTB2

Table 1. Summary of demographics for control and schizophrenia groups (mean \pm s.d.)

\begin{tabular}{|c|c|c|}
\hline & \multicolumn{2}{|c|}{ Whole cohort } \\
\hline & $\begin{array}{l}\text { Control group } \\
\quad(\mathrm{n}=38)\end{array}$ & $\begin{array}{l}\text { Schizophrenia group } \\
\qquad(\mathrm{n}=38)\end{array}$ \\
\hline Age (years) & $52.55 \pm 14.51$ & $52.24 \pm 14.52$ \\
\hline Brain pH & $6.68 \pm 0.27$ & $6.61 \pm 0.30$ \\
\hline PMI (hours) & $26.43 \pm 11.69$ & $28.21 \pm 13.57$ \\
\hline RIN & $7.59 \pm 0.83$ & $7.51 \pm 0.84$ \\
\hline $\begin{array}{l}\text { Freezer storage time } \\
\text { (months) }\end{array}$ & $69.57 \pm 42.73$ & $79.80 \pm 36.84$ \\
\hline Gender & $10 F ; 28 M$ & $13 F ; 25 M$ \\
\hline Hemisphere & 24R; 13L; 1NK & $18 \mathrm{R} ; 20 \mathrm{~L}$ \\
\hline Age of onset (years) & & $23.77 \pm 6.18$ \\
\hline $\begin{array}{l}\text { Duration of illness } \\
\text { (years) }\end{array}$ & & $27.09 \pm 13.99$ \\
\hline Atypical/typical & & $\begin{array}{c}\text { 4PAT; 22PT; 1AT; 7T; } \\
\text { 1T\&AT; 3NK }\end{array}$ \\
\hline Antidepressants & & 19Y; 16N; 3NK \\
\hline Syndrome & & 7Neg; 24P; 7NK \\
\hline \multicolumn{3}{|c|}{$\begin{array}{l}\text { Abbreviations: AT, atypical; F, female; L, left; } M \text {, male; } n \text {, number; } N \text {, no } \\
\text { Neg, negative; NK, not known; P, positive; PAT, predominantly atypical; PMI, } \\
\text { postmortem interval; PT, predominantly typical; R, right; RIN, RNA integrity } \\
\text { number; T, typical; Y, yes. } \\
\text { Presented as mean values } \pm \text { s.d. }\end{array}$} \\
\hline
\end{tabular}

emulsion (Kodak), dried, and developed using D-19 developer (Kodak) under strict dark conditions (no white light). Developed slides were Nissl counterstained with thionin.

\section{Image analysis for SST and PV mRNA expressions in OFC}

Optical density measurements on all autoradiograms were conducted blind to diagnosis. The cortical area (gray/white matter) within the gyrus rectus closest to the olfactory sulcus was sampled (Figure 1). ${ }^{9}$ For each section, three randomly placed lines were drawn perpendicular to the pial surface. Optical density measurements were recorded along the length of the lines traversing the entire cortical gray matter (olfactory sulcus). Optical density measurements were also performed in the gyrus rectus white matter for SST mRNA level. All the autoradiograms were calibrated for optical density using a radioactive ${ }^{14} \mathrm{C}$ standard $(\mu \mathrm{Ci} / \mathrm{g})$. Data for individual cortical lamina in the OFC were obtained using the percentage of the total cortical width occupied by each layer. ${ }^{9,10}$

SST mRNA positive (+) cell density was quantified using two-dimensional cell counting (Figure 2) in layer II of gyrus rectus in areas adjacent to both the olfactory and rostral sulci (see Supplementary Information for details).

\section{RNA extraction and quantitative reverse transcription PCR}

RNA extraction was carried out using TRlzol Reagent (Invitrogen Life Sciences, Melbourne, VIC, Australia). CDNA was generated using a SuperScript First-Strand Synthesis kit (Invitrogen, Carlsbad, CA, USA) as described in Weickert et al. ${ }^{40}$

Expression levels of inhibitory interneuron mRNAs (SST; PV) and apoptosis-related transcripts (FASR; TNFSF13) were determined by quantitative PCR (qPCR) in this study using published methods ${ }^{40}$ (see Supplementary Table S1). The averaged raw data were normalized to the geomean of expression levels of four housekeeper genes ( $\beta$-actin, TATA box-binding protein, ubiquitin C, and GAPDH; Supplementary Figure S2).

\section{Statistical analysis}

All statistical analyses were performed using Statistica (version 7.1; StatSoft, Tulsa, OK, USA). Tests for normality (Kolmogorov-Smirnov and Lilliefors) were conducted on raw data for all measures conducted in the OFC. Any non-normal raw data $(k$-s.d. $P<0.05)$ were log transformed and outliers within each diagnostic group removed. The number of excluded group outliers was between 1 and 3 individuals per group per measure.

Two-way analysis of variance was performed with diagnosis and hemisphere, or diagnosis and gender as between-groups independent variables. Pearson's correlations were performed to determine whether mRNA expression of markers quantified was related to demographic variables or other OFC measures (white matter-NeuN, GAD65/67; gray matter-GAD67). ${ }^{9}$ Daily or lifetime doses of antipsychotic medication were correlated with measures performed.

For any measure having a significant correlation with demographic variables, analysis of covariance was used to test for group differences. Analysis of variances/analysis of covariances with $P<0.05$ significance were further analyzed by Fisher least significant difference post hoc analysis to assess group differences.

\section{RESULTS}

SST mRNA expression is reduced in the OFC gray matter but elevated in the white matter in schizophrenia

From qualitative observation of the autoradiographic films, SST mRNA expression appeared to be punctate throughout the cortex and highest in layers II-III and V. The deep layer VI boundary and the superficial white matter boundary appeared diffuse without a distinct demarcation at the border between the gray matter and white matter (Figure 3a, b). The SST laminar mRNA expression pattern was consistent with earlier reports. ${ }^{13,41,42}$ The SST sense control produced no hybridization signal indicating riboprobe specificity for SST (Supplementary Figure S1A).

The mean SST mRNA expression level was significantly reduced across all cortical layers I-VI (Table 2A; Figure 3c) in people with schizophrenia relative to the controls. The magnitude of SST mRNA reduction was greatest in layer $\|(67 \% ; F(1,65)=160.31$, $P=3.31 \times 10^{-19}$; Table $2 \mathrm{~A}$ ) in schizophrenia. Consistent with this, 

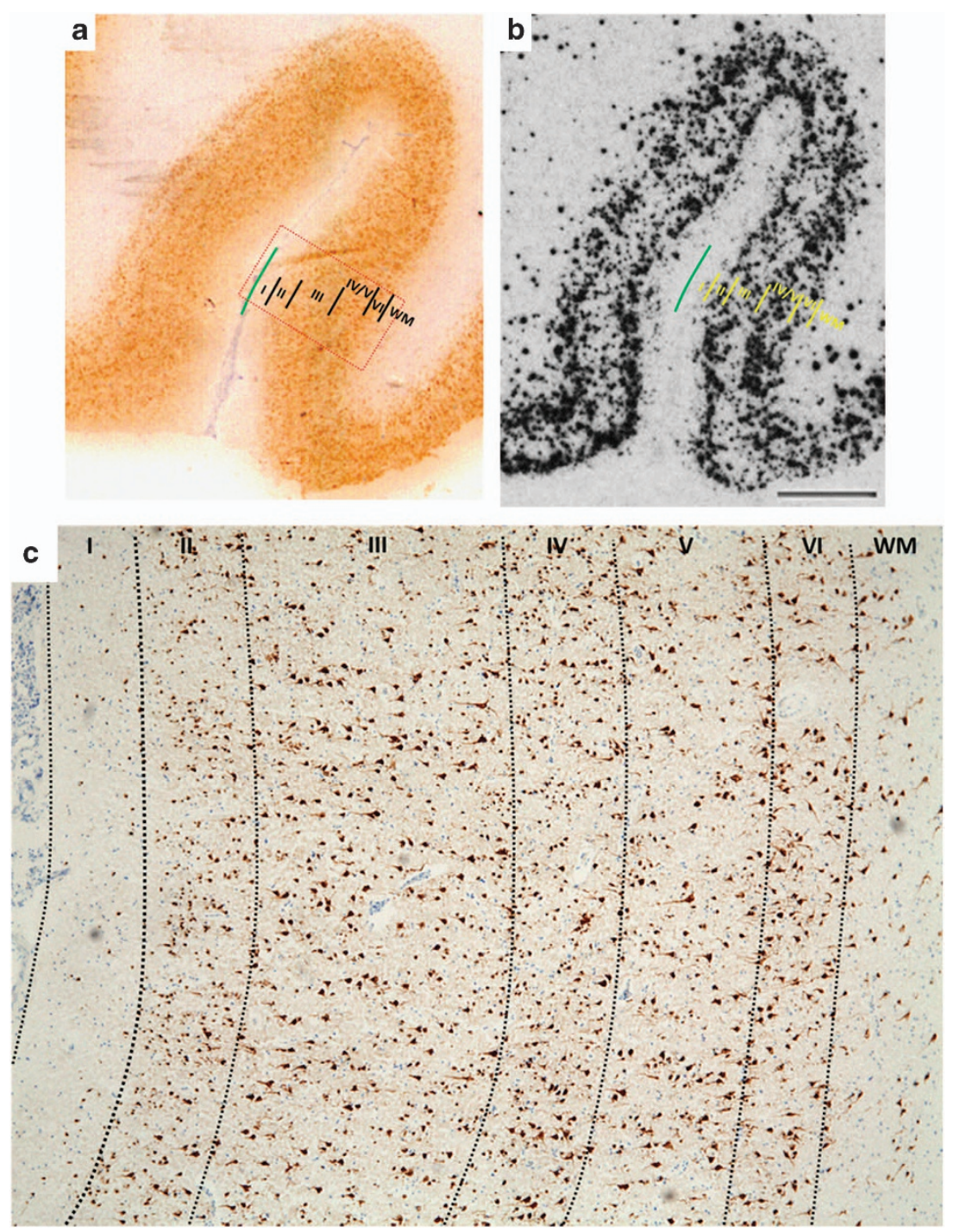

Figure 1. Representative images showing cortical lamina by (a) immunostaining (NeuN) and (b) in situ hybridization (somatostatin) in the orbital frontal cortex. (c) Orbitofrontal cortical lamina identification (layers I-VI) based on NeuN immunostaining (magnification $\times 4$ ). Red rectangular box in a represents the cortical area shown in c.

SST mRNA+ cell density was significantly reduced in the gyrus rectus layer II in people with schizophrenia compared with controls subjects (mean \pm s.d.: $16.54 \pm 11.04$ neurons $/ \mathrm{mm}^{2}$ versus $23.44 \pm 11.74$ neurons $/ \mathrm{mm}^{2} ; t=2.46, \mathrm{~d} f=64, P=0.02$; Figure $4 a$ ). Mean SST mRNA level for layers I-VI $(38 \% ; F(1,68)=29.63$, $\left.P=7.76 \times 10^{-7}\right)$ and by $\mathrm{qPCR}(17 \% ; t=2.04, \mathrm{~d} f=71, P=0.04$; Figure 4c) were also reduced in people with schizophrenia compared with controls. qPCR SST mRNA measurements in the OFC (Figure 4c) were consistent with the SST in situ hybridization mRNA measurements and positively correlated in people with schizophrenia $\left(r=0.77 ; P=5.0 \times 10^{-8}\right)$.

SST mRNA expression was detectable in the white matter in most sections and was significantly increased $(17 \% ; F(1,62)=$ $13.33, P=5.39 \times 10^{-4}$; Figure $4 \mathrm{~b}$; Table $2 \mathrm{~B}$ ) in people with schizophrenia relative to control subjects.

PV mRNA expression is reduced in cortical layers III and IV in schizophrenia

PV mRNA expression appeared to be highest in the middle cortical layers (layers III-V; Figure 3f). Unlike SST in situ mRNA expression, the gray matter and white matter boundaries were clearly demarcated, with no signal above background evident in the white matter in OFC (Figure 3d, e). Absence of signal in the PV sense control (Supplementary Figure S1B) and laminar expression pattern, consistent with previous reports, ${ }^{26,29}$ indicated specificity of the PV riboprobe used.

PV mRNA was significantly reduced in layers III $(18 \% ; t=2.59$, $\mathrm{d} f=64, P=0.01)$ and IV $\left(31 \% ; \mathrm{F}(1,64)=18.73, P=2.52 \times 10^{-5}\right)$ in people with schizophrenia compared with controls. PV mRNA measured by qPCR did not show a diagnostic difference $(t=-0.37$; $\mathrm{d} f=68 ; P=0.71$; Figure $4 \mathrm{~d}$ ) between schizophrenia (mean $=1.56 ; \mathrm{s}$. d. $=0.60)$ and control (mean $=1.52 ;$ s.d. $=0.47$ ) subjects.

FASR mRNA expression is elevated in the OFC in schizophrenia FASR mRNA expression was significantly increased in people with schizophrenia compared with control subjects (31\%; mean \pm s.d.: $1.67 \pm 1.01$ versus $1.28 \pm 0.58 ; t=-2.10, \mathrm{~d} f=71, P=0.04$; Figure $4 \mathrm{e}$ ). FASR mRNA expression positively correlated with TNFSF13 mRNA expression and interstitial white matter neuron NeuN density ${ }^{9}$ in the whole cohort (Table 3E). 


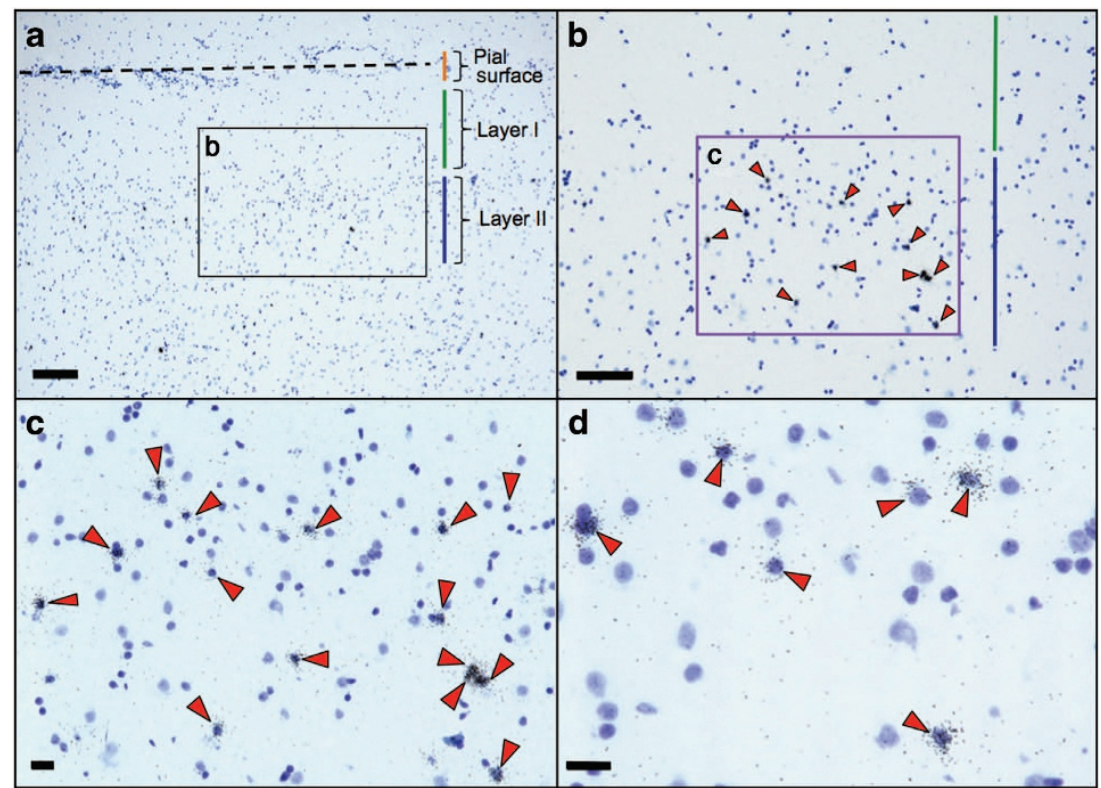

Figure 2. Somatostatin (SST) mRNA+ cell density quantification in orbital frontal cortex (OFC) layer II. Representative photomicrographs showing (a) OFC layer II (magnification $\times 4$; scale bar $=200 \mu \mathrm{m}$; dotted line represents olfactory sulcus; quantification was performed in the gyrus rectus gray matter layer II), (b) orientation of the quantification frame (purple framed box; magnification $\times 10$; $s c a l e$ bar $=100 \mu \mathrm{m}$ ), (c) SST mRNA+ neurons in the quantification frame (magnification $\times 20$; scale bar $=20 \mu \mathrm{m}$ ), and $(\mathbf{d}) \times 40$ magnified view (scale bar $=20 \mu \mathrm{m})$ showing SST mRNA+ neurons. Orange line indicates pial surface region (a), green line indicates OFC layer I region (a, b) and blue line indicates OFC layer II region $(\mathbf{a}, \mathbf{b})$. Red arrowheads $(\mathbf{b}-\mathbf{d})$ indicate SST mRNA+ neurons in OFC layer II.

a
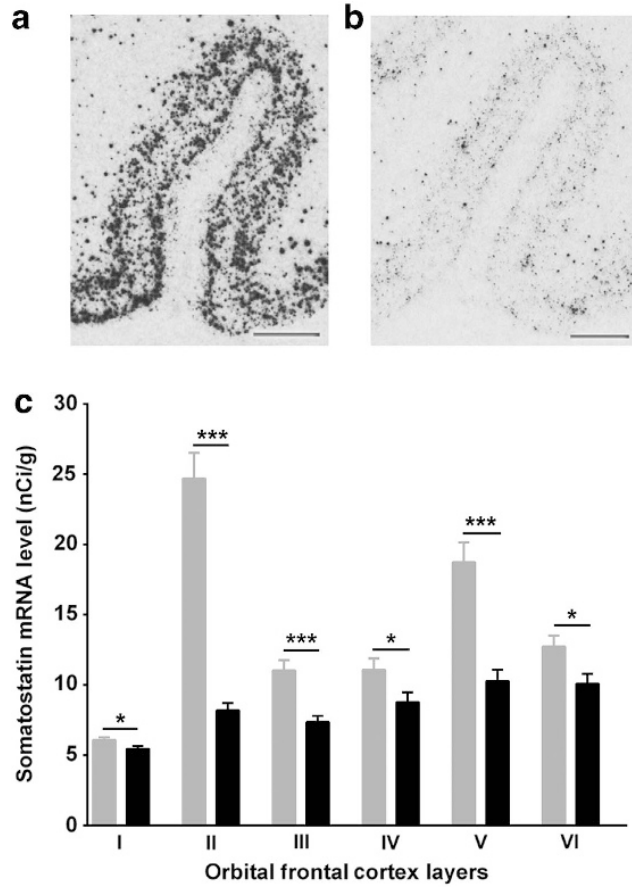

d
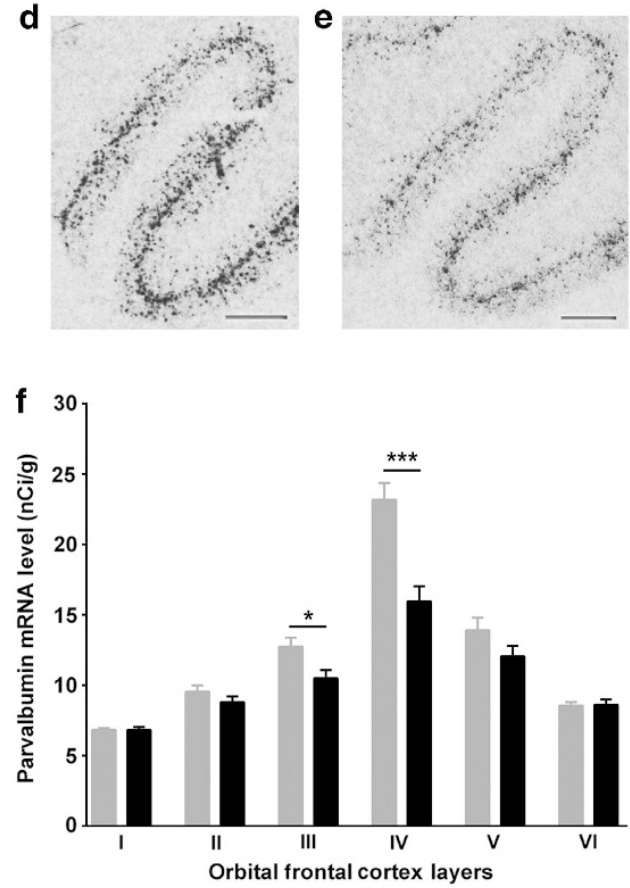

Figure 3. Representative in situ hybridization images showing somatostatin (SST: $a, b)$ and parvalbumin (PV: $d, e)$ mRNA distributions in human orbital frontal cortex in control (a, d) and schizophrenia (b, e) subjects, respectively. Laminar-specific SST (c) and PV (f) mRNA levels (nCi/g) in the gray matter in control (gray) and schizophrenia (black) subjects $\left({ }^{*} P<0.05 ;{ }^{* *} P<0.001\right)$. Scale bar $=2 \mathrm{~mm}$; error bars represent s.e.m.

There was no difference in TNFSF13 mRNA expression in people with schizophrenia compared with control subjects overall (mean \pm s.d.: $0.47 \pm 0.190$ versus $0.45 \pm 0.14 ; t=-0.515$, $\mathrm{d} f=72$, $P=0.61$; Figure $4 f)$.
Relationship between interneuron markers and cell death signaling mRNAs in the OFC

Next, we examined the relationship between SST mRNA expression (in situ hybridization-layer II and qPCR; Table 3A, B) and 


\begin{tabular}{|c|c|c|c|c|c|c|c|c|c|c|}
\hline & $\%$ Change & $\begin{array}{l}\text { Mean } \\
\text { control }\end{array}$ & $\begin{array}{c}\text { s.d. } \\
\text { control }\end{array}$ & $\begin{array}{c}\text { Mean } \\
\text { schizophrenia }\end{array}$ & $\begin{array}{c}\text { s.d. } \\
\text { schizophrenia }\end{array}$ & $\mathrm{t}$-value & $\mathrm{F}$ & $d f$ & P-value & Covariates \\
\hline \multicolumn{11}{|l|}{ (A) SST-layers } \\
\hline 1 & -10 & 6.07 & 1.22 & 5.45 & 1.17 & - & 5.09 & 66 & $0.03^{*}$ & $\mathrm{pH}$, age at death \\
\hline II & -67 & 24.69 & 11.10 & 8.20 & 2.97 & - & 160.31 & 65 & $3.31 \times 10^{-19 * * *}$ & $\begin{array}{l}\mathrm{pH} \text {, age at death, } \\
\text { RIN }\end{array}$ \\
\hline III & -60 & 11.03 & 7.61 & 4.39 & 2.85 & - & 16.55 & 65 & $1.31 \times 10^{-4 * * * *}$ & $\begin{array}{l}\mathrm{pH} \text {, age at death, } \\
\text { RIN }\end{array}$ \\
\hline IV & -21 & 11.08 & 4.86 & 8.78 & 4.13 & - & 4.63 & 68 & $0.04 *$ & $\mathrm{pH}$, age at death \\
\hline V & -45 & 18.75 & 8.58 & 10.29 & 4.60 & - & 24.99 & 66 & $4.51 \times 10^{-6 * * *}$ & $\begin{array}{l}\mathrm{pH} \text {, age at death, } \\
\mathrm{RIN}\end{array}$ \\
\hline $\mathrm{Vl}$ & -21 & 12.73 & 4.67 & 10.09 & 4.11 & - & 6.20 & 65 & $0.02 *$ & $\begin{array}{l}\mathrm{pH} \text {, age at death, } \\
\text { RIN }\end{array}$ \\
\hline (B) White matter & 17 & 6.50 & 1.06 & 7.62 & 1.88 & - & 13.33 & 62 & $5.39 \times 10^{-4 * * *}$ & $\mathrm{pH}$, age at death \\
\hline \multicolumn{11}{|l|}{ (C) PV-layers } \\
\hline 1 & 0 & 6.83 & 0.75 & 6.83 & 1.21 & - & 0.55 & 64 & 0.46 & PMI \\
\hline II & -8 & 9.54 & 2.68 & 8.81 & 2.28 & 0.60 & - & 65 & 0.55 & - \\
\hline III & -18 & 12.74 & 3.69 & 10.50 & 3.31 & 2.59 & - & 64 & $0.01 *$ & - \\
\hline IV & -31 & 23.18 & 6.74 & 15.97 & 6.14 & - & 18.73 & 63 & $5.48 \times 10^{-5 * * *}$ & $\mathrm{pH}$ \\
\hline $\mathrm{V}$ & -13 & 13.91 & 5.06 & 12.06 & 4.36 & - & 3.93 & 64 & 0.05 & Freezer (months) \\
\hline $\mathrm{VI}$ & 1 & 8.55 & 1.50 & 8.62 & 2.16 & - & 0.03 & 63 & 0.86 & Freezer (months) \\
\hline
\end{tabular}

Abbreviations: OFC, orbital frontal cortex; PMI, postmortem interval; PV, parvalbumin; RIN, RNA integrity number; SST, somatostatin.

${ }^{*} P<0.05 ;{ }^{* * *} P<0.001$.

other OFC mRNA measures (gray matter-FASR, TNFSF13, and GAD67). We also correlated superficial white matter neuron density measurements (NeuN; GAD65/67) $)^{9}$ performed in our earlier study with gray matter mRNA measurements from our current study to examine how increased white matter neuron density may be related to these measures (SST mRNA; SST mRNA+ cell density; PV mRNA; FASR mRNA) using the same postmortem brain tissue cohort. ${ }^{9}$ SST mRNA expression measured by qPCR negatively correlated with FASR and TNFSF13 mRNAs (Table 3A). SST layer II mRNA levels negatively correlated with FASR mRNA, TNFSF13 mRNA, and superficial white matter neuron density $\left(\right.$ NeuN; GAD65/67) ${ }^{9}$ in the whole cohort (Table 3B). FASR mRNA expression positively correlated with TNFSF13 mRNA and NeuN superficial white matter neuron density, ${ }^{9}$ but inversely with GAD67 (layers I-VI) ${ }^{9}$ mRNA levels in the OFC (Table 3E).

In contrast to SST mRNA, PV mRNA expression (qPCRTable 3D; in situ-Table 3E, F) did not correlate with death receptor signaling mRNAs (FASR; TNFSF13) or superficial white matter neuron density (Table 3D).

Consistent with our earlier study that demonstrated a negative correlation between brain $\mathrm{pH}$ and death receptor mRNAs, ${ }^{34}$ we found a significant negative correlation between TNFSF13 and FASR mRNA expressions and tissue $\mathrm{pH}$ ( $r$ value between -0.4 and $-0.5)$.

Statistical analysis revealed no significant relationship between measures quantified in the current study and antipsychotic medication, hemisphere, or gender $(P>0.05)$.

\section{DISCUSSION}

Main findings

The present study demonstrates that laminar SST mRNA (layers I-VI) deficits are more pronounced in magnitude and extent than PV mRNA (layers III and IV) deficits in the OFC in schizophrenia. These observations are consistent with our earlier observations demonstrating reduced inhibitory interneuron mRNAs (DIx1; GAD67; SST) in the OFC in three separate cohorts of people with schizophrenia. ${ }^{9-11}$ We provide evidence to show that the cell death receptor mRNA encoding FASR is elevated in the OFC in people with schizophrenia and, in particular, relates more strongly to SST mRNA than PV mRNA.

\section{Interpretation of findings}

Inhibitory interneuron pathology in the DLPFC in schizophrenia is well established, particularly involving SST and PV interneuron mRNAs. ${ }^{7,8,13,14}$ Data from independent postmortem cohorts suggest that the inhibitory interneuron subtype that is most affected in the prefrontal cortex in schizophrenia is SST, $8,11,14$ although this deficit also often includes PV mRNA., 14,29 Unlike SST expression that was reduced both by in situ hybridization and qPCR measurements, layer-specific (layers III and IV) reduction for PV was not evident in $\mathrm{qPCR}$ results in the current study. These results suggest that SST mRNA deficit may be a major contributor to the cortical inhibitory interneuron pathology found in the OFC of patients with schizophrenia. ${ }^{9,10}$ Our laminar SST mRNA measurements showed greatest reduction in layer II in people with schizophrenia, consistent with previous studies showing reduced gamma-aminobutyric acid (GABA)ergic neuron density in layer II in other cortical areas in schizophrenia. ${ }^{15,43,44}$ We therefore asked whether this reduction in SST mRNA translates into reduced SST mRNA+ cell density. Indeed, our results confirmed reduced SST inhibitory interneuron cell density in the OFC layer II in schizophrenia. PFC layer II non-pyramidal/interneuron-like neurons are known to be susceptible to cell damage or death ${ }^{45,46}$ and are among the last to differentiate in cortical development in humans. ${ }^{47}$ The deficit found in SST layer II interneuron density suggests that there could be a reduction in the number of inhibitory neurons in this layer.

Reduced cortical volume and neuronal loss have been associated with apoptosis ${ }^{20,33,48}$ potentially as a result of increased oxidative stress and excessive glutamatergic activity. ${ }^{49,50}$ In animal models of schizophrenia, NMDA receptor blockade (phencyclidine; ketamine; MK-801) has been shown to result in loss of inhibitory interneurons by apoptosis ${ }^{48,51}$ and behavioral deficits similar to schizophrenia in humans. ${ }^{51,52}$ A recent study from our laboratory demonstrated that increased death receptor signaling mRNAs (FASR; TNFSF13) were inversely related to both SST and PV mRNAs, ${ }^{34}$ known to be reduced in the DLPFC. ${ }^{8,11,14,30}$ In the OFC, 

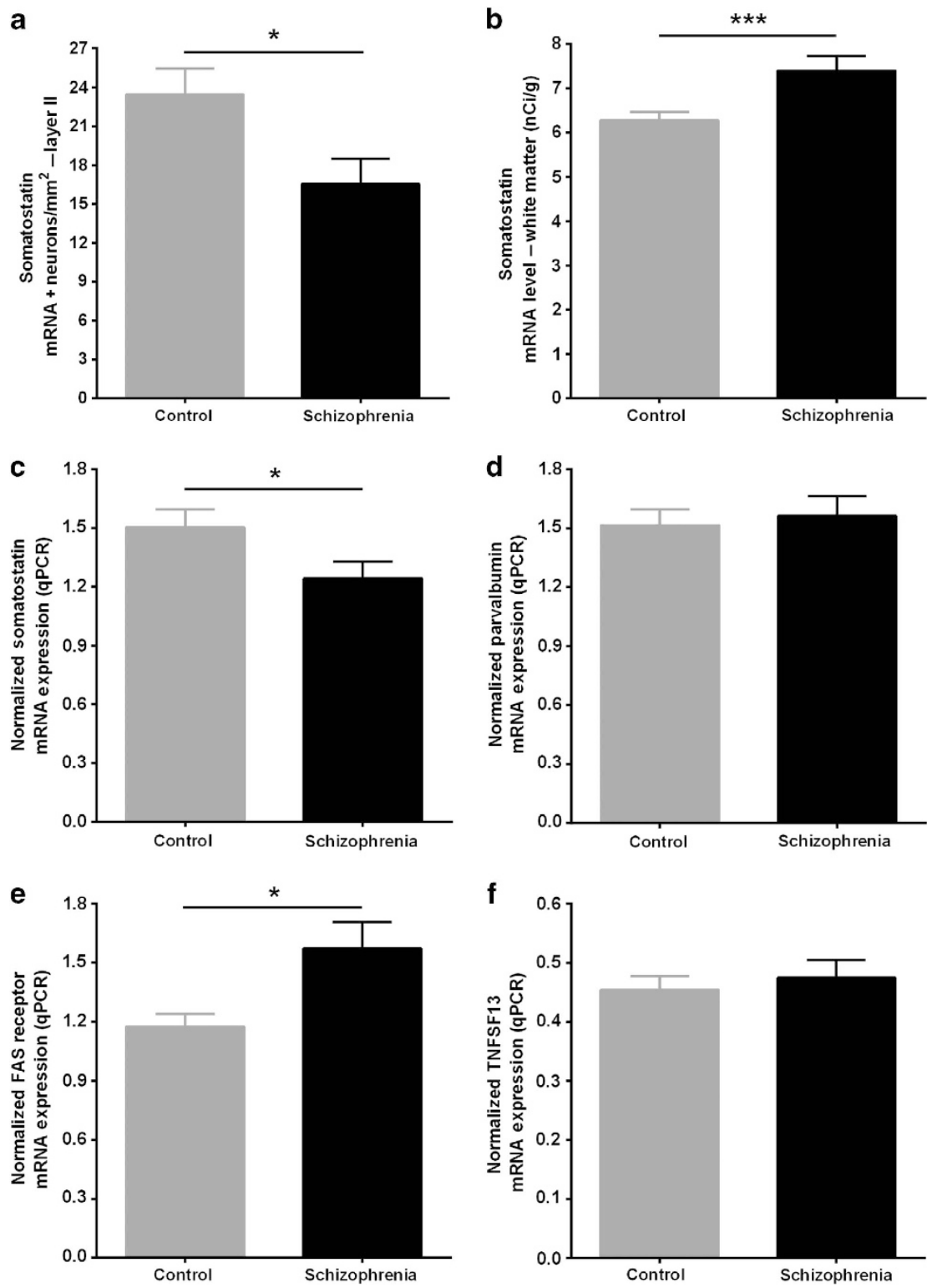

Figure 4. (a) Orbital frontal cortex (OFC) layer II somatostatin (SST) mRNA+ neuron density in OFC layer II (in situ hybridization). (b) SST mRNA expression in the white matter in human OFC. Quantitative PCR (qPCR) mRNA expression for (c) SST, (d) parvalbumin, (e) FAS receptor, and (f) TNFSF13 in schizophrenia (black) compared with control (gray) subjects in the OFC. Error bars represent s.e.m. ${ }^{*} P<0.05 ;{ }^{* * * P}<0.001$.

we found an increase in the FASR mRNA expression in schizophrenia. The death receptor signaling mRNAs (FASR and TNFSF13) quantified in the OFC inversely correlated with SST mRNA, but not with PV mRNA. More specifically, SST mRNA and SST mRNA+ cell density in layer II also showed a significant inverse relationship with the death receptor signaling mRNAs in people with schizophrenia. This suggests that, in our cohort, SST interneurons are vulnerable to the elevated death receptor signaling in the OFC resulting in putative neuronal loss as evident from our reduced SST mRNA+ cell density counts for layer II in schizophrenia. The relationship between death receptor signaling mRNAs and inhibitor interneuron markers determined in the current study suggests that reduction in SST mRNA is more specifically linked to elevated death receptor signaling mRNAs in the ventral (OFC) portions of the human frontal cortex as compared with the dorsal (DLPFC).

Multiple studies have demonstrated reduced inhibitory interneuron density in the cortices of people with schizophrenia, but without a testable hypothesis to account for this drop in neuronal density. ${ }^{15,17,20,22,27}$ Some studies that reported a reduction in GAD67 mRNA+ cell density interpreted the change in density to be due to reduced mRNA expression per cell (below levels of detection) with no change in cell density. ${ }^{23,28,29}$ Akbarian et al. ${ }^{23}$ drew this inference from their findings showing a significant reduction in GAD67 mRNA+ neurons (greatest in layer II) but no change in the total number of Nissl-stained neurons, whereas Volk et al. ${ }^{28}$ seemed to base their interpretation primarily on findings by Akbarian et al. $^{23}$ This interpretation was extended to subsequent studies showing reduced inhibitory interneuron density in people with schizophrenia. ${ }^{13,29,30,53,54}$ Interestingly, as calbindin mRNA expression ${ }^{8,11}$ as well as cell density ${ }^{55}$ have been shown to be elevated in the prefrontal cortex, it is possible that reduction in SST neuron density may be compensated for by an increased calbindin neuron density resulting in subtle or no significant overall changes in small Nissl-stained neurons in people with schizophrenia as reported by Akbarian et al. ${ }^{23}$ 
Table 3. (A) SST mRNA (qPCR), (B) SST layer II mRNA (in situ hybridization), (C) SST layer II mRNA+ cell density, (D) PV mRNA (qPCR), (E) FASR mRNA (qPCR), and (F) TNFSF13 (qPCR) correlation with other OFC measures

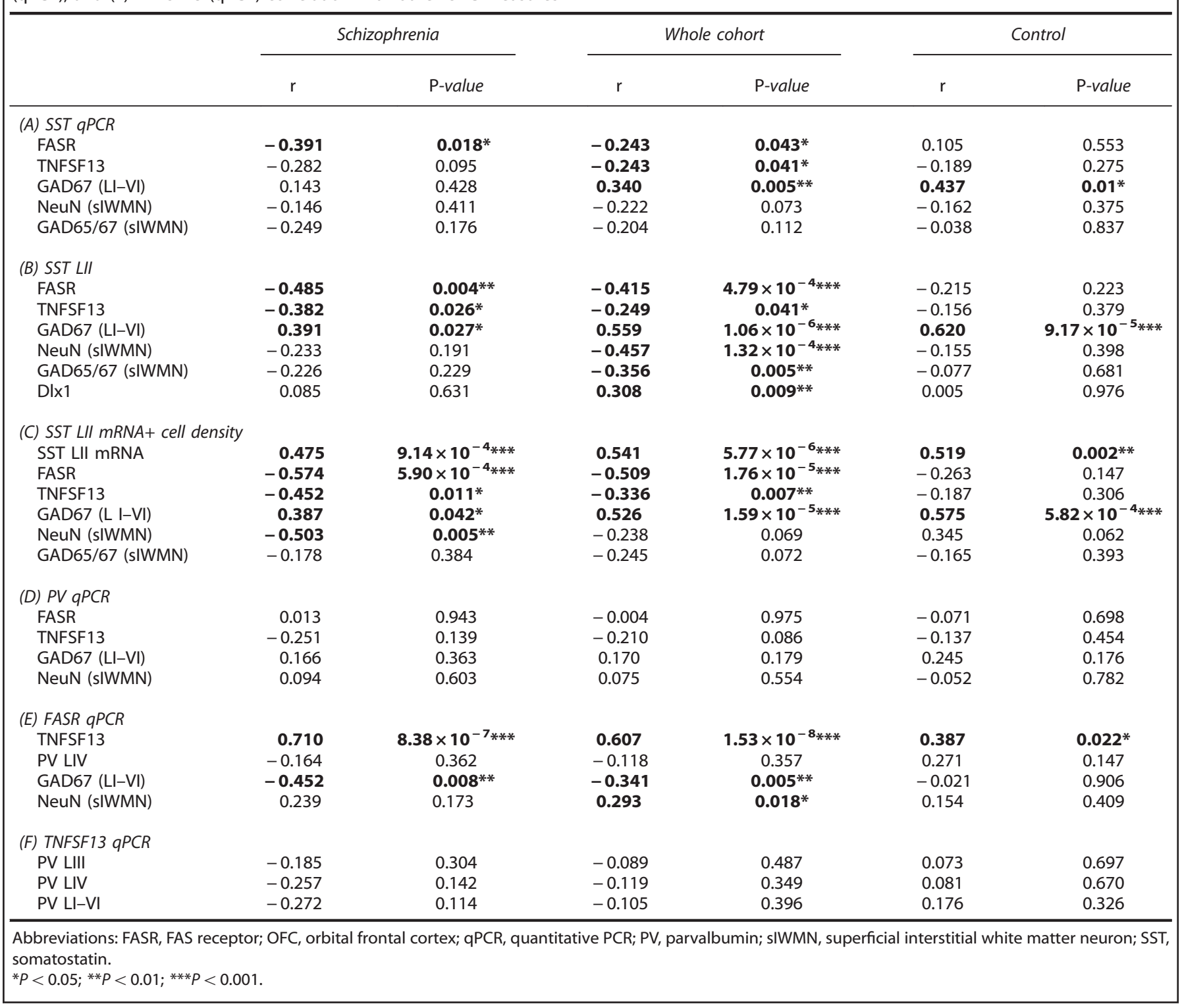

Although one study found a significant reduction in grain density per cell in PV mRNA+ neurons (22\%) with no change in PV mRNA+ neuron density, ${ }^{29}$ the same group of investigators reported a relatively similar reduction in grain density per cell in SST mRNA+ neurons (25 and $31 \%$ layer $\mathrm{V}$ and layer II, respectively) and a significant reduction in SST mRNA+ neuron density (23 and 26\%, respectively) in people with schizophrenia. ${ }^{13}$ Interestingly, reduction in both PV and SST mRNA+ neuron densities was interpreted as reduced mRNA expression beyond level of detection with no change in neuron density. Our findings in the OFC may explain these contrasting interpretations by Benes (loss of layer II nonpyramidal/interneuron-like neurons) ${ }^{20}$ and Akbarian/Lewis (reduced interneuron mRNAs below levels of detection without change in neuronal density) $)^{23,28}$ more appropriately, as our findings suggest that indeed there may be a loss of SST inhibitory interneuron subtype due to elevated death receptor signaling resulting in cell death, whereas other inhibitory interneuron subtypes may be unchanged or even increased resulting in no net change in small neuron density.

\section{Strengths and limitations}

Previous findings from our laboratory also demonstrate that the magnitude of another neuropathology, subcortical interstitial white matter neuron density increase, is more pronounced in the OFC.,11 In the OFC, we find that SST layer II mRNA+ neuron density and the superficial white matter neuron measures (NeuN; GAD65/67) ${ }^{9}$ are inversely correlated indicating that reduced SST mRNA+ neuron density in layer $I I$ is related to increased white matter neuron density. A limitation of our study is that we are unable to discern whether these two events are causally related to one another, nor are we able to completely rule out the effects of antipsychotic medications. It was difficult to detect TNFSF13 and FASR by immunohistochemistry due to its low abundance in the human postmortem brain tissue, as evident 
from the in situ hybridization conducted on human brain tissue. Lack of laminar mRNA expression data and protein measurement for TNFSF13/FASR/TUNEL labeling remains a limitation of our current study.

We found a significant laminar effect for PV mRNA expression (reduced in layers III and IV) in the OFC in schizophrenia, but not by qPCR. It is possible that the layer-specific effect found for PV mRNA expression in layers III and IV (mid-cortex) may be difficult to detect when using a homogenate-based mRNA measurement approach. This is consistent with our earlier observation in the DLPFC where we found that laminar-specific mRNA change (ErbB4-pan) can be diluted in homogenate-based measurement. ${ }^{46}$

\section{Conclusions}

To conclude, we provide evidence linking inhibitory interneuron deficits and elevated cell death signaling mRNAs in schizophrenia. These findings provide some support to earlier studies that found reduced inhibitory interneuron densities. ${ }^{7,13,54}$ The current study also brings forth death receptor signaling, involving FASR and TNFSF13 mRNAs, as a potential mechanism by which interneurons may be compromised in schizophrenia. The possible greater pathology in SST mRNA containing neurons as compared with PV containing neurons in people with schizophrenia may be a key finding to be taken into consideration when developing relevant animal models for schizophrenia. Our study also emphasizes that it may be informative to compare the extent of neuropathological changes across multiple brain regions in people with schizophrenia.

\section{ACKNOWLEDGMENTS}

We thank Mr Yiru Zhang and Ms Shan-Yuan Tsai for technical support.

\section{CONTRIBUTIONS}

DJ with CSW designed the study and wrote the protocol. DJ, VSC, and JCO performed the experiments. DJ and VSC wrote the first draft. DJ, VSC, and CSW were responsible for the data analysis. DJ, VSC, JCO, and CSW reviewed and revised the manuscript draft. Each of the authors have reviewed the manuscript and have approved the final manuscript.

\section{COMPETING INTERESTS}

The authors declare no conflict of interest.

\section{FUNDING}

This work was supported by Schizophrenia Research Institute (utilizing infrastructure funding from the NSW Ministry of Health and the Macquarie Group Foundation), the University of New South Wales, and Neuroscience Research Australia. CSW is a recipient of a National Health and Medical Research Council (Australia) Senior Research Fellowship. The New South Wales Tissue Resource Centre at the University of Sydney is supported by the National Health and Medical Research Council of Australia, Schizophrenia Research Institute, and National Institute of Alcohol Abuse and Alcoholism (grant number R24AA012725)

\section{REFERENCES}

1 Kringelbach ML, Rolls ET. The functional neuroanatomy of the human orbitofrontal cortex: evidence from neuroimaging and neuropsychology. Prog Neurobiol 2004; 72: 341-372.

2 Nakamura M, Nestor PG, Levitt JJ, Cohen AS, Kawashima T, Shenton ME et al. Orbitofrontal volume deficit in schizophrenia and thought disorder. Brain 2008, 131(Pt 1): 180-195.
3 Jackowski AP, Araújo Filho GM, Almeida AG, Araújo CM, Reis M, Nery F et al. The involvement of the orbitofrontal cortex in psychiatric disorders: an update of neuroimaging findings. Rev Bras Psiquiatr 2012; 34: 207-212.

4 Convit A, Wolf OT, de Leon MJ, Patalinjug M, Kandil E, Caraos C et al. Volumetric analysis of the pre-frontal regions: findings in aging and schizophrenia. Psychiatry Res 2001; 107: 61-73.

5 Gur RE, Cowell PE, Latshaw A, Turetsky BI, Grossman RI, Arnold SE et al. Reduced dorsal and orbital prefrontal gray matter volumes in schizophrenia. Arch Gen Psychiatry 2000; 57: 761-768.

6 Anderson SW, Bechara A, Damasio H, Tranel D, Damasio AR. Impairment of social and moral behavior related to early damage in human prefrontal cortex. Nat Neurosci 1999; 2: 1032-1037.

7 Yang Y, Fung SJ, Rothwell A, Tianmei S, Weickert CS. Increased interstitial white matter neuron density in the dorsolateral prefrontal cortex of people with schizophrenia. Biol Psychiatry 2011; 69: 63-70.

8 Fung SJ, Webster MJ, Sivagnanasundaram S, Duncan C, Elashoff M, Weickert CS. Expression of interneuron markers in the dorsolateral prefrontal cortex of the developing human and in schizophrenia. Am J Psychiatry 2010; 167: 1479-1488.

9 Joshi D, Fung SJ, Rothwell A, Weickert CS. Higher gamma-aminobutyric acid neuron density in the white matter of orbital frontal cortex in schizophrenia. Biol Psychiatry 2012; 72: 725-733.

10 Thompson M, Weickert CS, Wyatt E, Webster MJ. Decreased glutamic acid dec arboxylase67 mRNA expression in multiple brain areas of patients with schizophrenia and mood disorders. J Psychiatr Res 2009; 43: 970-977.

11 Fung SJ, Fillman SG, Webster MJ, Shannon Weickert C. Schizophrenia and bipolar disorder show both common and distinct changes in cortical interneuron markers. Schizophr Res 2014; 155: 26-30.

12 Hashimoto T, Arion D, Unger T, Maldonado-Aviles JG, Morris HM, Volk DW et al. Alterations in GABA-related transcriptome in the dorsolateral prefrontal cortex of subjects with schizophrenia. Mol Psychiatry 2008; 13: 147-161.

13 Morris HM, Hashimoto T, Lewis DA. Alterations in somatostatin mRNA expression in the dorsolateral prefrontal cortex of subjects with schizophrenia or schizoaffective disorder. Cereb Cortex 2008; 18: 1575-1587.

14 Hashimoto T, Bazmi HH, Mirnics K, Wu Q, Sampson AR, Lewis DA. Conserved regional patterns of GABA-related transcript expression in the neocortex of subjects with schizophrenia. Am J Psychiatry 2008; 165: 479-489.

15 Cotter D, Landau S, Beasley C, Stevenson R, Chana G, MacMillan L et al. The density and spatial distribution of GABAergic neurons, labelled using calcium binding proteins, in the anterior cingulate cortex in major depressive disorder bipolar disorder, and schizophrenia. Biol Psychiatry 2002; 51: 377-386.

16 Beasley CL, Reynolds GP. Parvalbumin-immunoreactive neurons are reduced in the prefrontal cortex of schizophrenics. Schizophr Res 1997; 24: 349-355.

17 Lewis DA. GABAergic local circuit neurons and prefrontal cortical dysfunction in schizophrenia. Brain Res Brain Res Rev 2000; 31: 270-276.

18 Lodge DJ, Behrens MM, Grace AA. A loss of parvalbumin-containing interneurons is associated with diminished oscillatory activity in an animal model of schizophrenia. J Neurosci 2009; 29: 2344-2354.

19 Reynolds GP, Abdul-Monim Z, Neill JC, Zhang ZJ. Calcium binding protein markers of GABA deficits in schizophrenia--postmortem studies and animal models. Neurotox Res 2004; 6: 57-61.

20 Benes FM, McSparren J, Bird ED, SanGiovanni JP, Vincent SL. Deficits in small interneurons in prefrontal and cingulate cortices of schizophrenic and schizoaffective patients. Arch Gen Psychiatry 1991; 48: 996-1001.

21 Konradi C, Yang CK, Zimmerman El, Lohmann KM, Gresch P, Pantazopoulos H et al. Hippocampal interneurons are abnormal in schizophrenia. Schizophr Res 2011; 131: 165-173.

22 Reynolds GP, Beasley CL. GABAergic neuronal subtypes in the human frontal cortex-development and deficits in schizophrenia. J Chem Neuroanat 2001; 22 95-100.

23 Akbarian S, Kim JJ, Potkin SG, Hagman JO, Tafazzoli A, Bunney WE Jr. Gene expression for glutamic acid decarboxylase is reduced without loss of neurons in prefrontal cortex of schizophrenics. Arch Gen Psychiatry 1995; 52: 258-266.

24 Rajkowska G, Selemon LD, Goldman-Rakic PS. Neuronal and glial somal size in the prefrontal cortex: a postmortem morphometric study of schizophrenia and Huntington disease. Arch Gen Psychiatry 1998; 55: 215-224.

25 Selemon LD, Rajkowska G, Goldman-Rakic PS. Abnormally high neuronal density in the schizophrenic cortex. A morphometric analysis of prefrontal area 9 and occipital area 17. Arch Gen Psychiatry 1995; 52: 805-818.

26 Woo TU, Miller JL, Lewis DA. Schizophrenia and the parvalbumin-containing class of cortical local circuit neurons. Am J Psychiatry 1997; 154: 1013-1015.

27 Benes FM, Vincent SL, Todtenkopf M. The density of pyramidal and nonpyramidal neurons in anterior cingulate cortex of schizophrenic and bipolar subjects. Bio Psychiatry 2001; 50: 395-406.

28 Volk DW, Austin MC, Pierri JN, Sampson AR, Lewis DA. Decreased glutamic acid decarboxylase67 messenger RNA expression in a subset of prefrontal cortical 
gamma-aminobutyric acid neurons in subjects with schizophrenia. Arch Gen Psychiatry 2000; 57: 237-245.

29 Hashimoto T, Volk DW, Eggan SM, Mirnics K, Pierri JN, Sun Z et al. Gene expression deficits in a subclass of GABA neurons in the prefrontal cortex of subjects with schizophrenia. J Neurosci 2003; 23: 6315-6326.

30 Lewis DA, Cruz DA, Melchitzky DS, Pierri JN. Lamina-specific deficits in parvalbumin-immunoreactive varicosities in the prefrontal cortex of subjects with schizophrenia: evidence for fewer projections from the thalamus. Am J Psychiatry 2001; 158: 1411-1422.

31 Akbarian S, Kim JJ, Pothin SG, Hetrick WP, Bunney WEJ, Jones EG. Maldistribution of interstitial neurons in prefrontal white matter of the brains of schizophrenic patients. Arch Gen Psychiatry 1996; 53: 425-436.

32 Margolis RL, Chuang DM, Post RM. Programmed cell death: implications for neuropsychiatric disorders. Biol Psychiatry 1994; 35: 946-956.

33 Benes FM. Development of the glutamate, GABA, and dopamine systems in relation to NRH-induced neurotoxicity. Biol Psychiatry 1995; 38: 783-787. receptor pathway in schizophrenia pathology. PLoS One 2012; 7: e35511.

35 Kelly K, Manos E, Jensen G, Nadauld L, Jones DA. APRIL/TRDL-1, a tumor necrosis factor-like ligand, stimulates cell death. Cancer Res 2000; 60: 1021-1027.

36 Mackay F, Ambrose C. The TNF family members BAFF and APRIL: the growing complexity. Cytokine Growth Factor Rev 2003; 14: 311-324.

37 Montgomery RI, Warner MS, Lum BJ, Spear PG. Herpes simplex virus-1 entry into cells mediated by a novel member of the TNF/NGF receptor family. Cell 1996; 87: 427-436.

38 Reich A, Spering C, Schulz JB. Death receptor Fas (CD95) signaling in the central nervous system: tuning neuroplasticity? Trends Neurosci 2008; 31: 478-486. 265-267.

40 Weickert CS, Sheedy D, Rothmond DA, Dedova I, Fung S, Garrick T et al. Selection of reference gene expression in a schizophrenia brain cohort. Aust NZ J Psychiatry 2010; 44: 59-70.

41 Hayes TL, Cameron JL, Fernstrom JD, Lewis DA. A comparative analysis of the distribution of prosomatostatin-derived peptides in human and monkey neocortex. J Comp Neurol 1991; 303: 584-599.

42 Lewis DA, Campbell MJ, Morrison JH. An immunohistochemical characterization of somatostatin-28 and somatostatin-28 (1-12) in monkey prefrontal cortex. J Comp Neurol 1986; 248: 1-18.

43 Beasley CL, Zhang ZJ, Patten I, Reynolds GP. Selective deficits in prefrontal cortical GABAergic neurons in schizophrenia defined by the presence of calcium-binding proteins. Biol Psychiatry 2002; 52: 708-715.
34 Catts VS, Shannon Weickert C. Gene expression analysis implicates a death

39 Lavrik I, Golks A, Krammer PH. Death receptor signaling. J Cell Sci 2005; 118(Pt 2):

44 Benes FM, Berretta S. GABAergic interneurons: implications for understanding schizophrenia and bipolar disorder. Neuropsychopharmacology 2001; 25: 1-27.

45 Cerqueira JJ, Pego JM, Taipa R, Bessa JM, Almeida OFX, Sousa N. Morphological correlates of corticosteroid-induced changes in prefrontal cortex-dependent behaviors. J Neurosci 2005; 25: 7792-7800.

46 Joshi D, Fullerton JM, Weickert CS. Elevated ErbB4 mRNA is related to interneuron deficit in prefrontal cortex in schizophrenia. J Psychiatr Res 2014; 53: 125-132.

47 Marin-Padilla M. Prenatal and early postnatal ontogenesis of the human motor cortex: a Golgi study. I. The sequential development of the cortical layers. Brain Res 1970; 23: 167-183.

48 Wang CZ, Yang SF, Xia Y, Johnson KM. Postnatal phencyclidine administration selectively reduces adult cortical parvalbumin-containing interneurons. Neuropsychopharmacology 2008; 33: 2442-2455.

49 Benes FM. Neurobiological investigations in cingulate cortex of schizophrenic brain. Schizophr Bull 1993; 19: 537-549.

50 Jiang Z, Cowell RM, Nakazawa K. Convergence of genetic and environmental factors on parvalbumin-positive interneurons in schizophrenia. Front Behav Neurosci 2013; 7: 116

51 Abekawa T, Ito K, Nakato Y, Koyama T. Developmental GABAergic deficit enhances methamphetamine-induced apoptosis. Psychopharmacology 2011; 215: 413-427.

52 Wang $\mathrm{CZ}$, Johnson $\mathrm{KM}$. The role of caspase-3 activation in phencyclidine-induced neuronal death in postnatal rats. Neuropsychopharmacology 2006; 32: 1178-1194.

53 Morris HM, Stopczynski RE, Lewis DA. NPY mRNA expression in the prefrontal cortex: selective reduction in the superficial white matter of subjects with schizoaffective disorder. Schizophr Res 2009; 115: 261-269.

54 Volk DW, Lewis DA. Early developmental disturbances of cortical inhibitory neurons: contribution to cognitive deficits in schizophrenia. Schizophr Bull 2014; 40: 952-957.

55 Daviss SR, Lewis DA. Local circuit neurons of the prefrontal cortex in schizophrenia: selective increase in the density of calbindin-immunoreactive neurons. Psychiatry Res 1995; 59: 81-96.

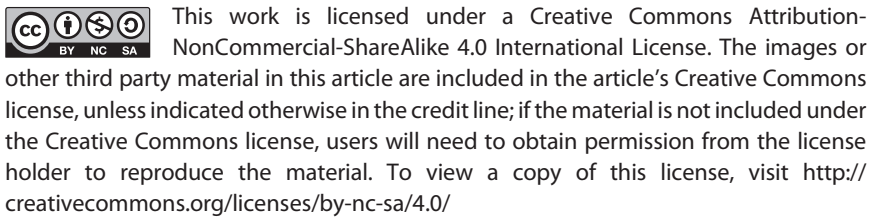

Supplementary Information accompanies the paper on the npj Schizophrenia website (http://www.nature.com/npjschz) 